\title{
Representações sociais sobre doação de órgãos e tecidos para transplantes entre adolescentes escolares
}

\section{Social representations of organs and tissues donation for transplantation among school adolescents}

\section{Diego Raone Ferreira ${ }^{a}$ \\ (iD) https://orcid.org/0000-000I-7633-2085 \\ E-mail: raonediegoœgmail.com \\ leda Harumi Higarashia \\ (D) https://orcid.org/0000-0002-4205-6841 \\ E-mail: iedaı6ı8®gmail.com}

anniversidade Estadual de Maringá. Programa de Pósgraduação em Enfermagem (PSE/UEM). Maringá, PR, Brasil.

\section{Correspondência}

Diego Raone Ferreira

Universidade Estadual de Maringá. Programa de Pós-graduação em Enfermagem (PSE/UEM). Avenida Colombo, 5790, Zona 7, Maringá.

Paraná, Brasil. CEP 87020-900

\section{Resumo}

Trata-se de uma pesquisa qualitativa, ancorada na Teoria das Representações Sociais, com o objetivo de analisar as possíveis representações sociais que adolescentes do Ensino Médio de uma escola da rede pública têm sobre o processo de doação de órgãos e tecidos para transplantes. Participaram do estudo 60 adolescentes, com idade entre 14 e 18 anos, matriculados no Ensino Médio de uma instituição de ensino situada no norte do Paraná. Os resultados, obtidos mediante técnica de associação livre de palavras, indicaram que o núcleo central das representações sociais em relação à doação de órgãos e ao ato de ser um doador de órgãos é composto por palavras que definem o sentido de amor, vida, solidariedade, compaixão, salvação, ajuda e, como elementos intermediários e periféricos, os vocábulos morte, sangue, esperança, felicidade e compaixão. Os resultados delineiam as possíveis representações sociais sobre doação de órgãos entre os adolescentes como um processo capaz de promover a recuperação da vitalidade humana, remetendo a sentimentos de gratidão e felicidade, inseridos numa sociedade mais consciente e solidária.

Palavras-chave: Representações Sociais; Enfermagem; Obtenção de Órgãos e Tecidos. 


\section{Introdução}

Anchored in the Theory of Social Representations, this qualitative research aims to analyze the possible social representations of adolescents enrolled in public high school regarding organ and tissue donations for transplantations. In total, 60 adolescents aged between 14 and 18 years, enrolled in a public high school in the north of Paraná were included in the study. Based on a word association technique, we verified the central nucleus of social representations regarding organ donation and being an organ donor to comprise words defining the meaning of love, life, solidarity, compassion, salvation, and help. In turn, words such as death, blood, hope, happiness, and compassion comprised intermediate and peripheral elements. In this sense, the social representation of organ donation among adolescents may be understood as a process capable of promoting the recovery of human vitality, referring to feelings of gratitude and happiness, inserted in a more conscious and caring society.

Keywords: Social Representations; Nursing; Organs and Tissues.
A saúde brasileira vem conquistando grandes avanços ao longo dos anos e, atrelada a essas transformações, a doação de órgãos e tecidos para transplantes surge como uma prática moderna, segura e eficaz para o tratamento de doenças que, de certo modo, colocam em risco a vitalidade humana. Apesar dessa prática aparecer associada à ideia de um aumento da perspectiva e qualidade de vida pós-transplante, ainda persistem diversas dúvidas, incertezas e medos que, face a sua complexidade, corroboram com a incompreensão do processo (Roza et al. 2010; Amaral et al. 2018).

É de conhecimento de grande parte da população que milhares de pessoas convivem com a esperança da concretização do transplante; porém, a realidade evidencia uma discrepância crescente entre o número de pessoas que aguardam por um órgão e o número de potenciais doadores. Apesar da doação de órgãos ser compreendida como uma possibilidade de recuperação, cura e aumento da expectativa de vida, ainda é necessário desmistificar esse processo no imaginário popular por meio da educação para doação de órgãos, uma vez que a efetivação do transplante depende do consentimento familiar para a doação (Amaral et al. 2018).

O Brasil ocupa a vice-liderança mundial no número de transplantes de órgãos e tecidos, ficando atrás apenas dos Estados Unidos (EUA). O recorte temporal de 2009 a 2019 mostra que o último ano foi um período marcante para o país conquistar este segundo lugar em números absolutos, quando foram efetivados 6.283 transplantes de rins, fígado (2.245), coração (378), pâncreas (173), pulmão (104), coração-pulmão (2), intestinos (2) 1 multivisceral e 14.943 córneas (ABTO, 2019).

O dimensionamento dos transplantes em 2019 revela que a saúde brasileira vem retomando o crescimento desde meados de 2015 e, conforme previsto, a taxa de doadores efetivos cresceu $6,5 \%$ no ano, alcançando 18,1 pmp (por milhão de população), 10,5\% abaixo dos 20 pmp previstos em 2016. A taxa de autorização familiar à doação de órgãos merece destaque com aumento de 7,1\%, atingindo, pela primeira vez, $60 \%$ das notificações. Um aspecto interessante a destacar é o perfil dos doadores no 
último quinquênio, com aumento de $8 \%$ para $13 \%$ de doadores falecidos com idade $>65$ anos (acréscimo de $62,5 \%$ ) e a diminuição de doadores pediátricos de $8 \%$ para $6 \%$ (redução de $25 \%$ ) (ABTO, 2019).

Dos estados brasileiros com notificação de potenciais doadores $>100$ pmp, o Distrito Federal e o estado do Paraná merecem destaque, respectivamente com 106,6 pmp e 102,7 pmp. Em relação às taxas de doadores efetivos $>40$ pmp, sobressai o estado de Santa Catarina com 47,2 pmp que também alcançou a taxa de efetivação da doação superior a 50\% (54\%) - e o estado do Paraná com $43,8 \%$. O número de autorização familiar superior a $70 \%$ tornou-se evidente nos estados de Santa Catarina (75\%), Paraná (74\%) e Rio de Janeiro (71\%). Os Estados que transcenderam os valores de referência para as respectivas taxas representam excelência na doação de órgãos e tecidos para transplantes e, consequentemente, estimulam outros estados a dedicarem-se a buscar melhores resultados (ABTO, 2019).

A Associação Brasileira de Transplantes de órgãos e Tecidos (ABTO) reconhece que o último trimestre de 2019 foi um determinante no ranking da doação de órgãos, sobretudo em decorrência da campanha de doação de órgãos do "Setembro Verde" e da ampla repercussão da efetivação da doação de órgãos e tecidos do apresentador Gugu Liberato, na Flórida (EUA). Entretanto, ainda assim, o país encerrou o período com 37.946 pessoas à espera de um ou mais órgãos (rim (25.163), fígado (1.178), coração (276), pulmão (187), pâncreas (18), pâncreas e rim (383) e córneas (10.741); além de 844 crianças ativas em listas de espera, sendo que destas, 320 esperam por rim, 41 (fígado), 57 (coração), 16 (pulmão) e 410 aguardam pelo transplante de córneas). Houve ainda um registro de 1.194 óbitos na faixa etária adulta e 77 óbitos pediátricos no duelo entre lista de espera e mortalidade em 2019 (ABTO, 2019).

A doação de órgãos e tecidos é um processo custeado e mantido pelos órgãos governamentais, com auxílio do Sistema Único de Saúde, que depende da confiança das pessoas para sua efetivação e do comprometimento dos profissionais de saúde frente ao diagnóstico da morte encefálica. No entanto, cabe destacar a necessidade de viabilizar novas políticas e ações de educação em saúde pró-doação, para conscientização da população sobre a importância do transplante como possibilidade de melhoria de vida para aqueles que necessitam, sobretudo para a redução dos índices de mortalidade nessa população (Brasil, 2017; Morais, Morais, 2012). Desse modo, questiona-se: como conscientizar a população, em especial os adolescentes, sobre o processo de doação de órgãos e tecidos para transplantes?

O estudo de representações sociais no contexto da doação de órgãos e tecidos para transplantes torna-se elemento chave quando o assunto é compreender a construção histórica e social de conceitos arquitetados na população, bem como aqueles propagados pela sociedade, ciência ou mídia. Por meio da investigação, interpretação e compreensão dos sentimentos, crenças e valores produzidos pela população é possível influenciar e conscientizar para a importância do consentimento à doação e da autodeclaração como doador de órgãos.

É de suma importância que se fomente o debate sobre a doação, a autorização e a autodeclaração de doador nos diversos espaços públicos da nossa sociedade, principalmente nas escolas, universidades, e ambientes de trabalho, para que se possa aprofundar a discussão sobre a temática, de modo a aniquilar barreiras, preconceitos e estereótipos negativos construídos em torno desse processo.

O ambiente escolar favorece a divulgação e disseminação de informações, sobretudo aquelas relacionadas à Saúde. No que diz respeito à educação para doação e transplantes de órgãos e tecidos, a escola pode exercer um importante papel no rompimento de paradigmas negativos e deturpados sobre o processo, uma vez que integra indivíduos em intenso processo de evolução biológica, psicológica e social (Moraes, Gallani, Meneghin, 2006; Nogueira, et al. 2016).

Partindo deste pressuposto, busca-se analisar as possíveis representações sociais que adolescentes do Ensino Médio de uma escola da rede pública têm do processo de doação de órgãos e tecidos para transplantes.

\section{Materiais e métodos}

Para alcançar os objetivos deste estudo, optou-se por uma pesquisa de caráter qualitativo, ancorada na Teoria das Representações Sociais, proposta 
por Moscovici (1961) e amplamente propagada por Jodelet (2015) e Jovchelovitch (2013), que possibilita identificar inúmeros caminhos e traços comuns à representação coletiva face a distintos estímulos, como fotografias, desenhos, sons e técnicas capazes de compreender e (re)significar os fenômenos sociais e a sua relação com a sociedade (Moscovici, 2015).

A Teoria das Representações Sociais (TRS) teve origem na Europa, a partir da publicação de "La Psychanalyse: Son image et son public" de Serge Moscovici, em meados 1961, fortemente apoiada por precursores da ciência social em todo o território Francês, como Durkheim. As representações sociais configuram uma ciência social que distingue o mundo moderno do mundo medieval, por meio de uma fonte profícua de representações culturais e sociais de um coletivo, que permitem compreender o homem enquanto ser social e a sua relação com o mundo (Farr, 2013).

As possíveis representações construídas acerca de um determinado objeto configuram um sistema de interpretação que, diante de uma abordagem estrutural, busca compreender a concepção dos indivíduos em relação a sentimentos, condutas e comportamentos manifestos em seu meio. Dessa forma, Jean-Claude Abric, em 1976, adiciona à teoria original uma contribuição ímpar para a compreensão conceitual e metódica daquilo que é representado nas relações do sujeito com os sujeitos, do sujeito com o mundo e do sujeito com os fenômenos, denominada Teoria do Núcleo Central das Representações (apud Silva, Machado, 2016).

Participaram do estudo 60 adolescentes matriculados no Ensino Médio de uma escola da rede pública, situada no interior do Estado do Paraná, com idade entre 14 e 18 anos, de ambos os sexos. Os participantes elegíveis foram abordados mediante indicação da coordenação pedagógica escolar, seguindo atendimento de critérios relacionados à acessibilidade, à logística, ao interesse e à disponibilidade dos adolescentes e professores em prosseguir com as etapas da pesquisa.

Inicialmente, agendou-se um breve encontro com os adolescentes em sala de aula, com o propósito de esclarecer a metodologia e o objetivo da pesquisa. Em seguida, foi apresentado o Termo de Consentimento Livre e Esclarecido (TCLE), para conhecimento e consentimento dos pais, responsáveis e dos participantes quando maiores de idade e o Termo de Assentimento Livre e Esclarecido (TALE) para assinatura e anuência dos responsáveis e participantes menores de idade, ambos com informações e orientações referentes a todas as etapas e procedimentos da intervenção.

A obtenção dos dados ocorreu no primeiro semestre de 2018, mediante aplicação do instrumento baseado na Técnica de Associação Livre de Palavras (TALP), pautado na Teoria das Representações Sociais, defendida por Sá (1996a, 1996b) e Moscovici (2015), com o intuito de identificar os elementos nucleares centrais e periféricos. Para tal, foram aplicados dois estímulos indutores: "escreva até cinco (5) palavras (sentimentos, palavras, imagens) que vêm à sua cabeça quando você pensa em 'doação de órgãos' e escreva até cinco (5) palavras (sentimentos, palavras, imagens) que vem à sua cabeça quando você pensa em 'sou um doador de órgãos"”.

As palavras evocadas foram organizadas com auxílio de planilhas eletrônicas e randomizadas com auxílio do Software Ensembre de Programmes Permettant I'Analyse dês Êvocations (Evoc), elaborado por Pierre Vergès (2002), o qual possibilita a compreensão do núcleo central e os sistemas periféricos que compõem as Representações Sociais dos adolescentes a respeito da doação de órgãos e tecidos para transplantes.

O Software Evoc possui em sua composição dezesseis subprogramas com distintas finalidades. Para a realização da presente análise, optou-se por utilizar cinco: Lexique, que unificou as palavras pertencentes à mesma estrutura de conhecimento; Trievoc, tratou as palavras evocadas, no sentido de organizá-las por ordem alfabética; Nettoie, eliminou possíveis erros de digitação, unificando vocábulos que possuem mesmo sentido e retirando acentuações, já que o próprio programa não exige o uso; Rangmot, organizou as palavras evocadas em ordem alfabética, pelo número e ordem de evocação, fornecendo também, a frequência total de cada uma, de acordo com média a ponderada da ordem de evocação, frequência total e ordem média das evocações (Machado, Aniceto, 2010; Silva, Machado, 2016).

Logo após, os dados foram agrupados e distribuídos em um sistema denominado "quadro de quatro casas" ou diagrama de Vergès, com o uso 
do último subprograma, RANGFRQ, que organizou as palavras que compõem o núcleo central e os elementos periféricos das Representações Sociais.

Este estudo atendeu a todas as normas regulamentadoras determinadas pelas Resoluções 466/2012 e 510/2016 do Conselho Nacional de Saúde (CNS), que estabelecem as diretrizes éticas para a realização de estudos com seres humanos e foi aprovado pelo Comitê Permanente de Ética em Pesquisa envolvendo Seres Humanos (COPEP) da Universidade Estadual de Maringá (UEM), sob o protocolo $\mathrm{n}^{\mathrm{o}}$. 87692018.1.0000.0104.

\section{Resultados}

Dos 60 adolescentes que participaram da pesquisa, houve predominância do sexo feminino, com 38 participantes $(63,3 \%)$, e 22 do sexo masculino (36,6\%). A idade variou entre 14 e 18 anos, sendo prevalente a faixa etária dos 16 anos (38,3\%) e apenas um $(1,7 \%)$ já atingira a maioridade.

Em relação à escolarização, 25 adolescentes cursavam o $2^{\circ}$ ano do Ensino Médio (41,7\%), $19(31,7 \%)$ o $1^{\circ}$ ano e $16(26,7 \%)$ estavam regularmente matriculados no $3^{\circ}$ ano. Apenas 19 participantes (31,7\%) associavam atividades laborais formais e informais à escolarização, os demais declararam apenas estudar (68,3\%). Dentre os componentes do grupo, a religião católica mostrou-se prevalente, com 37 adolescentes $(61,7 \%)$, seguidos respectivamente por 20 evangélicos (33,3\%) e dois ateus (3,3\%). Apenas um participante declarou não possuir religião $(1,7 \%)$.

Quanto à moradia, 25 adolescentes relataram residir com os pais e irmãos (41,7\%), 13 informaram residir apenas com os pais $(21,7 \%)$, e com a mãe e irmãos foram 10 participantes $(16,7 \%)$. Seis adolescentes moravam apenas com a mãe (10\%), quatro eram provenientes de outras organizações familiares $(6,7 \%)$ e dois residiam em lares habitados pelo pai e irmãos (3,3\%). No que se refere à escolarização parental, 33,3\% dos pais concluíram o Ensino Médio, 16,7\% eram graduados e 8,3\% possuíam apenas o Ensino Fundamental. Já os demais responsáveis, correspondendo a 41\%, não concluíram os respectivos anos de escolarização.

Em relação à apresentação e análise das representações sociais, o diagrama resultante da aplicação do $\varepsilon V O C$ é composto por um quadro de “quatro casas" que agrupa os elementos de núcleo central, intermediários e periféricos de uma possível representação social. No primeiro quadrante encontram-se os elementos que foram citados com maior frequência e prontamente vieram à lembrança dos adolescentes, constituindo o possível núcleo central. Respectivamente, a segunda casa agrupa as palavras que durante a associação obtiveram alta frequência, porém, citadas em últimas posições, já na terceira casa, encontram-se as palavras que foram citadas em baixa frequência, mas que foram evocadas primeiramente. Os elementos mais afastados do núcleo central formaram a quarta casa do diagrama, denominada "periferia distante" (Silva, Machado, 2016).

A Teoria do Núcleo Central das Representações defende que as representações se organizam em torno de um sistema constituído por um núcleo central e elementos periféricos. O núcleo central agrupa elementos representados a partir da memória coletiva, refletindo suas condições históricas, sociais e culturais, de forma coerente e cristalizada, sendo, portanto, estável e resistente a modificações, independente do contexto em que se encontra. Nesse sentido, o núcleo central desempenha o papel de gerar ou transformar uma representação, de determinar a relação dos elementos que constituem uma representação, além da "função estabilizadora que assegura a permanência de seus elementos e protege o núcleo central, fazendo com que ele se mantenha rígido, não se modifique facilmente" (Sá, 1996a; Sá, 1996b; Silva, Machado, 2016, p. 143).

Já o sistema periférico forma-se em torno do sistema central e constitui-se em elementos da representação que integram as histórias individuais, as experiências e a realidade concreta ao sistema central. Os elementos periféricos apresentam uma maior flexibilidade, além de se demonstrar sensível ao ambiente imediato, na medida em que se adapta à realidade e diferencia o conteúdo de uma representação. De um ponto de vista específico, pode-se afirmar que o sistema periférico protege o núcleo central (Sá, 1996a; Sá, 1996b).

Para Silva e Machado (2016), o sistema periférico aproxima aquilo que, de certa forma, é representado à realidade, uma vez que este funciona como uma “ponte" entre o que é vivenciado, experienciado e 
sentido em relação a um determinado fenômeno e o núcleo central. De modo geral, observa-se que, de acordo com a Teoria do Núcleo Central, as representações sociais são determinadas por elementos oriundos do binômio sujeito e sociedade, como as crenças, valores, cultura, opiniões, condutas e sentimentos que organizam as representações em um sistema formado por um núcleo central e um sistema periférico, carregando funções distintas, ao mesmo tempo específicas e complementares entre si.
Mediante a aplicação do termo indutor “doação de órgãos”, registrou-se um total de 238 palavras evocadas que, após serem submetidas ao subprograma Lexique, resultaram em 60 palavras que se assemelhavam entre si. Com o auxílio do RANGFRQ, essas palavras foram agrupadas em quatro quadrantes, o que possibilitou analisar os possíveis grupos que compõem as Representações Sociais, atendendo a dois critérios básicos: Frequência $(\mathrm{F}=10)$ e Ordem Média de Evocações $(\mathrm{OME}=2,5)$.

\section{Quadro I - Distribuição das possíveis Representações Sociais sobre "Doação de Órgãos"}

Primeira Casa - Núcleo Central

Alta f e baixa Ordem Média de Evocações

F"10 e OME"2,5

\begin{tabular}{|c|c|c|c|c|c|}
\hline Grupo de Palavras & $\mathbf{F}$ & OME & Grupo de Palavras & $\mathbf{F}$ & OME \\
\hline Amor & 18 & 2,22 & Morte & 10 & 2,60 \\
\hline Vida & 13 & 2,30 & & & \\
\hline Solidariedade & 12 & 2,16 & & & \\
\hline Compaixão & 10 & 2,30 & & & \\
\hline Salvação & 10 & 2,30 & & & \\
\hline
\end{tabular}

Terceira Casa - Elementos Intermediários

Baixa f e baixa Ordem Média de Evocações

F"10 e OME"2,5

\begin{tabular}{|l|c|l|l|c|c|}
\hline Grupo de Palavras & F & OME & Grupo de Palavras & F & OME \\
\hline Sangue & 8 & 2,22 & Esperança & 2,66 \\
\hline Empatia & 7 & 2,30 & Bondade & 9 & 2,55 \\
\hline Carinho & 6 & 2,16 & Cirurgia & 8 & 3,12 \\
\hline Caridade & 5 & 2,30 & Medo & 7 & 2,85 \\
\hline Coração & 5 & 2,30 & Coragem & 5 & 2,80 \\
\hline
\end{tabular}

As palavras que integram a primeira casa do Quadro 1 correspondem àquelas que foram citadas com maior frequência e prontidão pelos adolescentes, tendo sua origem ligada a sentimentos cristalizados no ideário desse grupo de jovens sobre a doação de órgãos, constituindo o núcleo central das representações. Na segunda casa agrupou-se o vocábulo representado pela alta ordem média de evocações e, na terceira casa, as palavras associadas
Segunda Casa - Elementos Intermediários Alta f e alta Ordem Média de Evocações F"10 e OME" 2,5

Quarta Casa - Elementos Periféricos

Baixa F e Alta Ordem Média de Evocações F"IO e OME" 2,5

à baixa frequência e baixa ordem média de evocações, ambas constituindo os elementos intermediários das representações.

Os elementos periféricos das representações, ou seja, aqueles que foram pouco evocados, porém com alta ordem média de evocações, integraram a quarta casa do diagrama de Vergès. Os vocábulos de grupos periféricos, apesar de distantes, caracterizam-se como elementos indispensáveis que estruturam, 
atualizam e contextualizam o núcleo central, "permitindo uma diferenciação em função das experiências cotidianas nas quais os indivíduos estão imersos. Em poucas palavras, os elementos do sistema periférico fazem a interface entre a realidade concreta e o sistema central" (Machado, Aniceto et al. 2010, p. 357).
Ao empregar o termo “sou um doador de órgãos”, obtiveram-se 234 palavras que, após submetidas ao subprograma Lexique, foram unificadas em 60 vocábulos. O RANGFRQ tabulou e organizou esses vocábulos por meio de suas Frequências $(F=10)$ e Ordem Média de Evocações $(\mathrm{OME}=2,5)$ em quatro casas, conforme apresentado no Quadro 2.

\section{Quadro 2 - Distribuição das possíveis Representações Sociais sobre "Sou Doação de Órgãos"}

\begin{tabular}{|c|c|c|c|c|c|}
\hline \multicolumn{3}{|c|}{ Primeira Casa - Núcleo Central } & \multicolumn{3}{|c|}{ Segunda Casa - Elementos Intermediários } \\
\hline \multicolumn{3}{|c|}{ Alta f e baixa Ordem Média de Evocações } & \multicolumn{3}{|c|}{ Alta f e alta Ordem Média de Evocações } \\
\hline \multicolumn{3}{|l|}{ F "10 e OME " 2,5} & \multicolumn{3}{|l|}{ F"10 e OME "2,5 } \\
\hline Grupo de Palavras & $\mathbf{F}$ & OME & Grupo de Palavras & $\mathbf{F}$ & OME \\
\hline Amor & 30 & 1,93 & Felicidade & 13 & 2,61 \\
\hline Ajudar & 10 & 1,90 & Gratidão & 10 & 3,00 \\
\hline \multicolumn{3}{|c|}{ Terceira Casa - Elementos Intermediários } & \multicolumn{3}{|c|}{ Quarta casa - Elementos Periféricos } \\
\hline \multicolumn{3}{|c|}{ Baixa f e baixa Ordem Média de Evocações } & \multicolumn{3}{|c|}{ Baixa F e Alta Ordem Média de Evocações } \\
\hline \multicolumn{3}{|l|}{ F "10 e OME " 2,5} & \multicolumn{3}{|c|}{ F "10 e OME " 2,5} \\
\hline Grupo de Palavras & $\mathbf{F}$ & OME & Grupo de Palavras & $\mathbf{F}$ & OME \\
\hline Compaixão & 9 & 2,44 & Esperança & 9 & 3,22 \\
\hline Salvação & 7 & 2,42 & Solidariedade & 9 & 2,55 \\
\hline Orgulho & 6 & 2,33 & Coragem & 6 & 2,66 \\
\hline Vida & 5 & 2,40 & Empatia & 6 & 2,66 \\
\hline Alegria & 5 & 2,40 & Hocnital & & 200 \\
\hline Doação & 5 & 1,60 & HOSpllal & 5 & 3,00 \\
\hline
\end{tabular}

Conforme o Quadro 2, observa-se que os vocábulos mencionados com maior frequência e que vieram prontamente à lembrança dos adolescentes foram organizados na primeira casa, passando a integrar o possível núcleo central das representações. Posteriormente, os elementos intermediários ao núcleo central foram agrupados na segunda casa do diagrama de Vergès e, na terceira casa, agrupou-se os elementos intermediários, ou seja, aqueles que representam núcleos de evocação com baixa frequência e menor ordem de evocação. Na quarta e última casa do diagrama foram organizados os elementos periféricos representados pela baixa frequência e alta ordem média de evocações.

\section{Discussão}

A adolescência é compreendida como uma fase de constante transformação biopsicossocial em que o ser humano vivencia alterações físicas e emocionais refletidas em sentimentos e comportamentos incompreendidos. Os adolescentes integram uma população socialmente ativa que, quando expostos a meios e situações diversas, como redes sociais, rodas de conversa ou, até mesmo, a riscos que desafiam a morte, podem se transformar em disseminadores potenciais de informações positivas, influenciando as práticas sociais de seus grupos e da sociedade como um todo (Nogueira et al. 2016). 
É natural que o processo de doação de órgãos e tecidos para transplantes não se configure como um assunto comum entre os jovens, que tendem a demonstrar maior interesse por temas relacionados ao entretenimento, às drogas e à sexualidade. No entanto, para ampliar a conscientização desta notória parcela da sociedade sobre o papel da doação e transplante de órgãos entre aqueles que precisam, optou-se por introduzir a temática no âmbito escolar e investigar o posicionamento dos adolescentes, buscando delinear uma possível representação a respeito da doação de órgãos e sobre a decisão de ser um doador.

Quando estimulados pelo termo disparador “doação de órgãos” foi possível observar que o núcleo central das representações sociais de adolescentes estrutura-se em elementos positivos, associando-se à capacidade de colocar-se no lugar do outro, revelando sentimentos de "amor", "solidariedade" e "compaixão". Esses sentimentos indicam que, para os adolescentes participantes desse estudo, a doação de órgãos é compreendida como um ato de amor, solidariedade e compaixão em relação ao próximo, também como um meio de devolver a qualidade de vida para aqueles que esperam por um órgão (Melo et al. 2012).

Coadunado a estes sentimentos sabe-se que o processo doação e transplante representa um momento marcado por uma série de fatores estressores, envolvendo aquele que ansiosamente aguarda um órgão e seus familiares e aqueles que, no mesmo momento, vivenciam a perda de um ente querido, tornando-se, assim, um potencial doador.

Nessa perspectiva, o diagnóstico de morte encefálica advém permeado por uma multiplicidade de sentimentos, como a revolta, impotência, perda, inutilidadee, em grande parte dos casos, incompreensão; remetendo à importância de uma abordagem adequada, capaz de acolher e amparar a dor da perda recente. Entretanto, mediante um consentimento favorável à doação de órgãos, os sentimentos de dor e sofrimento da família enlutada dão lugar a outros, que são eles o amor ao próximo, solidariedade, compaixão e bemestar, graças à sensação de salvar a vida de outra pessoa (Melo et al. 2012).

Uma pesquisa realizada com adolescentes espanhóis, matriculados no Ensino Médio na Espanha, que possui a maior taxa de doadores por população, evidenciou que $46 \%$ dos jovens declararam-se favoráveis à doação em virtude de valores pró-sociais como solidariedade, vida após a morte, obrigação moral e reciprocidade. Para os autores, desenvolver ações educativas nessa fase da vida é fundamental para sensibilizar atitudes, deixando-os a par da carência de órgãos para atender à fila de espera, considerando que a palavra solidariedade foi o valor encorajador pró-doação e, reciprocidade, no sentido de que futuramente essa população também pode precisar de um órgão (Febrero et al., 2019).

Tendo esse cenário como plano de fundo, observase que as palavras "vida" e "salvação" também ilustram o núcleo central das representações. Para os adolescentes, a decisão favorável à doação constitui uma atitude que permite salvar e prolongar a qualidade de vida de alguém que anseia por essa nova oportunidade.

Maynard et al. (2015) ressaltam que, com os avanços científicos e tecnológicos da saúde no mundo, o corpo humano pós-morte deixou de ter como destino único o sepultamento ou a cremação, uma vez que pode contribuir com a recuperação, cura ou qualidade de vida por intervenção do processo doação-transplante. A doação de órgãos possibilita atribuir um novo significado à morte, atenuando por vezes a intensa sensação da perda e o processo do luto, promovendo, de certa forma, a aceitação por meio da atitude altruísta e humana de salvar uma outra vida.

Nesse sentido, com as possíveis representações dos adolescentes diante do termo indutor "doação de órgãos", observou-se que a "morte" e doação apresentam-se como elementos integradores desse processo. Tais elementos são indissociáveis e refletem diretamente na conjuntura do processo de doação, já que a notificação de um potencial doador somente se dá a partir da constatação de uma morte encefálica.

A morte, quando ocorre em faixas etárias mais avançadas, é encarada como um processo natural do viver humano, colocando fim a um ciclo formado pelos atos de nascer, crescer, envelhecer e morrer. Ao contrário, na juventude, a morte é compreendida como algo devastador, sobretudo por interromper precocemente os sonhos, as oportunidades, as realizações e a vida de um adolescente, contrariando 
o ciclo natural do desenvolvimento da vida humana (Bittencourt et al. 2015).

Mesmo que a morte seja considerada um dos únicos infortúnios concretos que marcam a existência humana, ela ainda é pouco compreendida no contexto social, pois carrega o papel de findar o ciclo vital humano. Culturalmente, a morte é compreendida como a parada irreversível de todos os órgãos do corpo humano, o que faz com que a confirmação da morte encefálica com a subsistência dos batimentos cardíacos precise ser desmistificada no ideário da população, com o pressuposto de aniquilar qualquer desejo de recusa decorrente da incompreensão deste evento (Maynard et al. 2015; Bittencourt et al. 2015).

A doação de órgãos representa a possibilidade de atenuar sentimentos usuais deste processo, como a revolta, a raiva, a perda, a impotência e a negação, que passam então a ser moldados pelas representações sociais que fazem referência ao ato de doar órgãos como um posicionamento que envolve sentimentos de empatia, carinho, caridade, esperança, bondade e coragem, que pode salvar vidas (Roza et al. 2010; Bittencourt et al. 2015).

Esses sentimentos, expressos pelos adolescentes em suas possíveis representações sobre o tema, denotam um sentido de "solidariedade, grandeza e espírito de nobreza humana”, já que o referido processo estimulou os mesmos a realizarem um exercício de alteridade, imaginando-se diante da realidade daqueles que esperam por um órgão. Tal prática levou à consolidação de concepções da doação como atitude de bondade e coragem que, de modo geral, representa o amor fraterno em benefício do bem-estar, saúde e vida de outra pessoa (Moraes, Gallani, Meneghin, 2006; Garcia et al. 2015, p. 199).

Quando colocados frente ao termo indutor "doação de órgãos e tecidos para transplantes" os adolescentes também evocaram, em suas possíveis representações, a palavra "coração". Presumivelmente, a população jovem considera esse órgão, sobretudo pela sua complexidade e relevância para o organismo, como um dos principais responsáveis pela vitalidade humana. Essa realidade novamente reafirma a hipótese de que grande parte da sociedade associa a morte à ausência dos batimentos cardíacos, o que pode contribuir significativamente para a incompreensão do diagnóstico de morte encefálica, fragilizando o processo doação-transplante.

Dentre os elementos periféricos, os adolescentes evocaram as palavras "cirurgia" e "medo", trazendo à tona o temor pela morte de um ente querido e, até mesmo, da possibilidade de sua própria terminalidade, uma vez que doações e transplantes post-mortem estão condicionados à morte (Bittencourt et al. 2015). Além da relação do medo da morte, a referência à cirurgia associase, provavelmente, a sentimentos comuns a este procedimento complexo, invasivo e desencadeador de medos e incertezas presentes durante todo seu percurso e desfecho. A complexidade de uma cirurgia faz germinar na sociedade diferentes fantasias que revelam sentimentos de aversão e medo frente a situações dolorosas ou associadas ao ambiente hospitalar, aos procedimentos invasivos e, também, aos profissionais de saúde (Garanhani, Valle, 2012).

0 "medo" também foi um valor predominante entre os adolescentes escolares espanhóis como um dos fatores que pode afetar a atitude em relação à doação de órgãos, tendo em vista que $24 \%$ referiramse ao medo da morte, em específico, e $14 \%$ rejeição à doação devido à ideia de mutilação corporal. Desse modo, entende-se que as pessoas podem ser motivadas por preocupações errôneas que podem declinar atitudes em relação à doação de órgãos e tecidos, ressaltando novamente a necessidade de disseminar boas informações e esclarecer a sociedade e família, principalmente sobre o medo e a manipulação do corpo, evitando impactos negativos no processo (Febrero et al., 2019).

Quando os adolescentes foram estimulados pelo termo indutor "ser um doador de órgãos", estes novamente evocaram sentimentos como "amor" e “ajudar" (o próximo). Reiterando o posicionamento anterior, os adolescentes manifestaram, em suas possíveis representações, um posicionamento favorável à doação/decisão de serem doadores de órgãos. Tais representações traduziam um sentido de amor e empatia pelo próximo, uma vez que o consentimento e a prática do processo doação-transplante remetiam à ideia de serem responsáveis por promoverem a recuperação, cura e qualidade de vida de outro indivíduo (Melo et al., 2012; Morais, Morais, 2012). 
Outra questão importante e que merece destaque é o agrupamento das palavras "felicidade" e "gratidão", que se apresentam como elementos intermediários das representações sociais de ser um doador de órgãos, eliminando o sentimento representado pela palavra "morte", que figurava nos elementos intermediários da segunda casa, ao tratarem/refletirem sobre a doação de órgãos. Tal aspecto corrobora a hipótese de que a doação é compreendida como uma decisão embasada no amor, na compaixão, na solidariedade e na empatia de que, realimentando a esperança, a qualquer momento alguém pode vir e consentir a doação. Os motivos pelos quais os adolescentes demonstraram-se favoráveis ao processo reúne uma gama de sentimentos, mas que convergem com a finalidade de ajudar o próximo e salvar vidas (Nogueira et al., 2016; Garcia et al., 2015).

Quanto aos elementos intermediários, representados na terceira casa, os sentimentos de "orgulho" e "alegria" foram evocados pelos adolescentes. Partindo destas representações, entende-se que a concretização da doação proporciona àquele que depende de um órgão a oportunidade de olhar o mundo com outros olhos, ou seja, vendo no transplante a esperança de uma nova vida. Dessa forma, os adolescentes compreendem que a doação significa carregar dentro de si o desejo altruísta de exercer a solidariedade e de "fazer o bem sem olhar a quem”. Na perspectiva desta população, a doação e o transplante de órgãos são concebidos como um processo que revigora os sentimentos de gratidão daqueles que recebem, e de orgulho daqueles que corroboram para a prática do bem na sociedade.

Como elemento periférico das representações, o vocábulo "hospital" fez-se presente no ideário da comunidade jovem, sugerindo que os adolescentes já compreendem que o processo doação-transplante é efetivado em ambiente hospitalar. É notório também que, por detrás dessa representação, advém o temor a procedimentos decorrentes da hospitalização, como o próprio ambiente hospitalar e a aversão ao sangue e materiais perfurocortantes, incluindo riscos de morte daqueles que doam em vida e de seus receptores. Tais sentimentos, ainda que apareçam de forma periférica, devem ser igualmente considerados, na medida em que podem indicar elementos capazes de influenciar negativamente a doação.
Sendo assim, para neutralizar imagens e compreensões negativas acerca da doação ou do ato de ser um doador de órgãos, chama-se a atenção para o diálogo em ambientes sociais e familiares, que tem demonstrado duplo efeito positivo: fornecer esclarecimentos embasados em informações seguras a respeito da doação de órgãos e motivar atitudes e comportamentos em relação ao processo. Promover momentos de discussão na esfera familiar permite aos adolescentes manifestar suas concepções e atitudes em relação à doação e ao transplante e, também conhecer o pensamento e comportamento de seus responsáveis, podendo refletir em momentos decisivos de suas vidas (Febrero et al., 2019).

\section{Considerações finais}

A doação de órgãos e tecidos para transplantes é compreendida como um processo que possibilita a recuperação da depreciação do organismo, do ponto de vista físico e psicológico, em função da perda parcial ou total de órgãos sadios e que exercem forte influência na vitalidade humana. No entanto, a reposição desses órgãos dá-se mediante a prática da doação, que depende, por sua vez, da autorização familiar que advém coadunada a um processo de conscientização e mobilização da sociedade.

Sendo assim, depreende-se que a promoção da conscientização e as transformações de práticas e paradigmas na sociedade somente se dará por meio de ações e intervenções educativas de caráter continuado, que alcancem as diversas esferas e grupos sociais. Destacam-se, neste processo, a escola e a adolescência como lócus profícuo à disseminação de novas ideias e comportamentos capazes de beneficiar a sociedade a médio e longo prazo, sobretudo por constituírem-se como população predominante em redes sociais, círculos de amizades, rodas de conversa e no convívio familiar.

Os resultados desta pesquisa evidenciaram que os elementos nucleares das possíveis representações sociais dos adolescentes sobre o processo doaçãotransplante estão vinculados, mais fortemente, a sentimentos de amor, solidariedade e compaixão, revelando, também, o desejo altruísta deles em se autodeclararem como futuros doadores de órgãos. 
Nesse ínterim, ao conceber a escola como um ambiente integrador importante no processo de formação de cidadãos mais conscientes, ratifica-se a participação indispensável dos profissionais de saúde como agentes que podem fortalecer as relações intersetoriais, disseminando conhecimentos e promovendo a educação em saúde.

Sendo este estudo um recorte de uma realidade extremamente ampla e rica em oportunidades investigativas e de intervenção, sugere-se a realização de novos estudos que explorem a interface escola-saúde. Conclui-se, também, que a metodologia utilizada permitiu o alcance do objetivo proposto, podendo ser replicada em outros contextos com vistas para transformação do cenário da doação de órgãos.

\section{Referências}

AMARAL, A. P. S. et al. Desafios encontrados no processo de doação de órgãos: relato de experiência. Rev Lecturas: Educación Física y Deportes, Buenos Aires, v. 23, n. 244, p. 86-97, 2018.

BITTENCOURT, A. L. P.; QUINTANA, A. M.; VELHO, M. T. A. C. A perda do filho: luto e doação de órgãos. Rev Estudos de Psicologia, Campinas, v. 28 , n. 4, p. 435-442, 2011. DOI: 10.159o/So103166X2011000400004

\section{ABTO. ASSOCIAÇÃO BRASILEIRA DE}

TRANSPLANTE DE ÓRGÃOS. Registro Brasileiro de Transplantes. Dimensionamento dos Transplantes no Brasil e em cada Estado (2012-2019). São Paulo: Associação Brasileira de Transplante de Órgãos, 2019. Disponível em: <http://www.abto.org.br/ abtovo3/Upload/file/RBT/2019/RBT-2019-leitura. pdf >. Acesso em: 14 ago. 2020.

FARR, R. M. Representações sociais: a teoria e sua história. In: Textos em Representações Sociais. Pedrinho A. Guareschi; Sandra Jovchelovitch (Org.). 14. ed. Petrópolis: Vozes, 2013. p. 31-59.

FEBRERO, B. et al. Psychological profile of teenagers toward organ donation: a multicentric study in Spain. European Journal of Public Health, Reino Unido, v. 29, n. 6, p. 1011-1018, 2019. DOI: 10.1093/eurpub/ckzo36
GARANHANI, M. L.; VALLE, E. R. M. O significado da experiência cirúrgica para a criança. Rev Cienc Cuid Saude, Maringá, v. 11, suplemento, p. 259-266, 2012. DOI: 10.4025/cienccuidsaude.v11i5.17084

GARCIA, V. D. G. et al. Religião e transplantes. In: Doação e Transplantes de Órgãos e Tecidos. Clotilde Druck Garcia; Japão Drose Pereira; Valter Duro Garcia (Org.). São Paulo: Segmento Farma, 2015. p.197-207.

MACHADO, L. B.; ANICETO, R. A. Núcleo central e periferias das representações sociais de ciclos de aprendizagem entre professores. Rev Ensaio: aval. pol. públ. educ, Rio de Janeiro, v. 18, n. 67 , p. 345-364, 2010. DOI: 10.1590/So10440362010000200009

MAYNARD, L. O. D. et al. Os conflitos do consentimento acerca da doação de órgãos post mortem no Brasil. Rev Dir Sanit, São Paulo, v. 16, n. 3, p. 122-144, 2016. DOI: 10.116o6/issn.23169044.v16i3p122-144

MELO, G. B. et al. Os sentimentos das pessoas que aguardam por um órgão ou tecido na fila única de transplantes. JBT Jor Bras Transpl, São Paulo, v. 15, n. 3, p. 1651-1688, 2012.

MORAES, M. W.; GALLANI, M. C. B. J.; MENEGHIN, P. Crenças que influenciam adolescentes na doação de órgãos. Rev Esc Enferm USP, São Paulo, v. 4o, n. 4, p. 484-492, 2006.

MORAIS, T. R.; MORAIS, M. R. A importância da educação na promoção da doação de órgãos. Rev Bras em Promoção da Saúde, Fortaleza, v. 25, n. 3 , p. 251-252, 2012. DOI: 10.5020/18061230.2012.p251

MOSCOVICI, S. Representações Sociais: investigação em psicologia social/Serge Moscovici; editado em inglês por Gerard Duveen; traduzido do inglês por Pedrinho A. Guareschi. 11. ed. Petrópolis: Vozes, 2015.

NOGUEIRA, M. A. et al. Conhecimento e posicionamentos de adolescentes sobre doação de órgãos antes e após uma ação educativa. Rev Enferm Atenção Saúde, Uberaba, v. 5, n. 2, p. 57-72, 2016. DOI: 10.18554/reas.v5i2.156o 
ROZA, B. A. et al. Doação de órgãos e tecidos: relação com o corpo em nossa sociedade. Rev Acta Paul Enferm, São Paulo, v. 23, n. 3, p. 417-422, 2010. DOI: 10.1590/So103-21002010000300017

SÁ, C. P. Núcleo Central das Representações

Sociais. Petrópolis, RJ: Vozes, 1996 a.
SÁ, C. P. Representações Sociais: teoria e pesquisa do núcleo central. Rev Temas em Psicologia, Ribeirão Preto, v. 4, n. 3, p. 19-33, 1996b.

SILVA, I. M. B.; MACHADO, L. B. Compromisso e amor como elementos centrais das representações de ser professora de educação infantil. Rev $\varepsilon d u c$. Foco, Juiz de Fora, v. 20, n. 3, p. 137-164, 2016.

DOI: $10.22195 / 2447-52462016019608$

\section{Contribuição dos autores}

Ferreira e Higarashi contribuíram para a elaboração do projeto, coleta e análise dos dados e redação do artigo. Higarashi também foi responsável pela orientação de todas as etapas.

Recebido: 06/04/2021

Reapresentado: 09/06/2021

Aprovado: 14/06/2021 